University of Nebraska - Lincoln

DigitalCommons@University of Nebraska - Lincoln

Parameterization on of Energy Balance Components and Remote Sensing in Systems Modeling

Jerry L. Hatfield

USDA-ARS, jerry.hatfield@ars.usda.gov

Follow this and additional works at: https://digitalcommons.unl.edu/usdaarsfacpub

Hatfield, Jerry L., "Parameterization on of Energy Balance Components and Remote Sensing in Systems Modeling" (2011). Publications from USDA-ARS / UNL Faculty. 1371.

https://digitalcommons.unl.edu/usdaarsfacpub/1371

This Article is brought to you for free and open access by the U.S. Department of Agriculture: Agricultural Research Service, Lincoln, Nebraska at DigitalCommons@University of Nebraska - Lincoln. It has been accepted for inclusion in Publications from USDA-ARS / UNL Faculty by an authorized administrator of DigitalCommons@University of Nebraska - Lincoln. 


\title{
Parameterization of Energy Balance Components and Remote Sensing in Systems Modeling
}

\author{
Jerry L. Hatfield
}

\begin{abstract}
Estimation of a number of parameters using simulation models has proven to be a valuable source of information from which we can assess the impact of scenarios that would be difficult to determine experimentally, or for which it would be difficult to conceptualize an appropriate experiment design. However, simulation models require extensive inputs that are not always easily found or exist at the spatial or temporal resolution needed for the models. Many simulation models require energy inputs that represent the energy balance of the surface, and there have been several attempts to derive different inputs. There have been various methods to estimate solar radiation from combinations of air temperature, altitude, and precipitation. Albedo has been estimated from several different methods using either combinations of reflectance or simple regression models. Long-wave radiation from the atmosphere has been estimated using regression models of vapor pressure and air temperature. Many of these parameterizations have been derived using locally available data, and efforts are needed for broader evaluation of these methods. Crop simulation models produce a variety of estimates for plant growth; among these are leaf area index, biomass, and ground cover. These parameters can be measured directly, often a laborious task and not at the scale needed for model evaluation, or they can be estimated from remotely sensed observations. This approach not only provides an independent measure of the crop parameters to compare with model simulations, but a potential feedback into the model simulation to help correct the model over time. Challenges remain in our efforts to improve models and provide the input necessary to further our ability to understand the complexities of the interactions in the soil-plant-atmosphere continuum.
\end{abstract}

This article is a U.S. government work, and is not subject to copyright in the United States.

J.L. Hatfield, USDA-ARS, National Laboratory for Agriculture and the Environment, 2110 University Blvd., Ames, IA 50011 (jerry.hatfield@ars.usda.gov).

doi:10.2134/advagricsystmodel2.c9

Copyright (C) 2011. ASA, CSSA, SSSA, 5585 Guilford Rd., Madison, WI 53711-5801, USA.

Methods of introducing system models into agricultural research. L.R. Ahuja and L. Ma (ed.)

Advances in Agricultural Systems Modeling Series 2. 


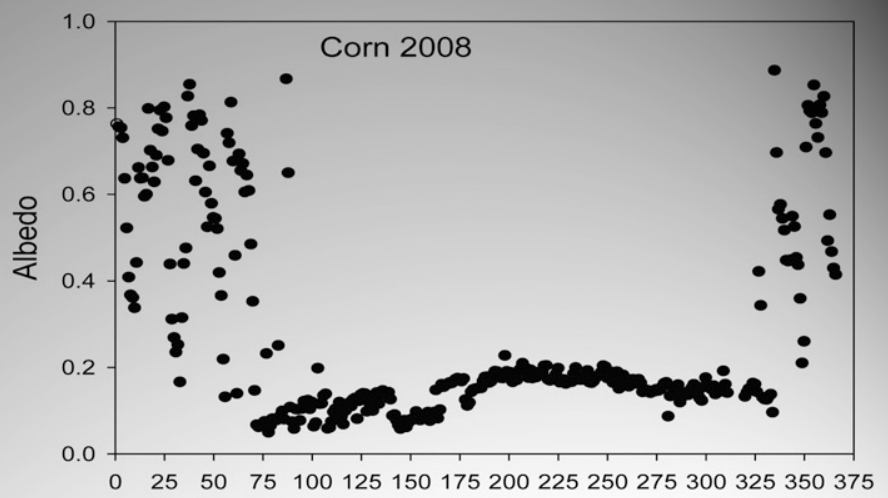

Day of Year

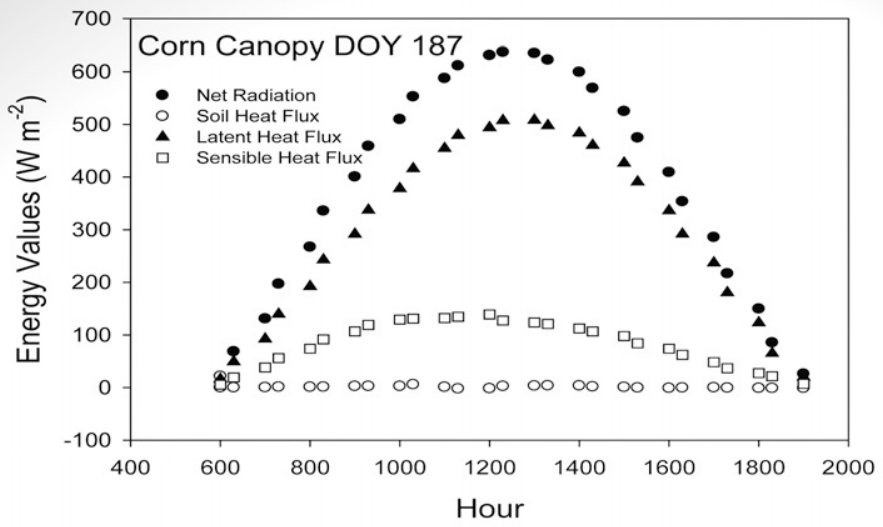


imulation models provide a valuable tool for assessing the interactions among complex processes in the soil-plant-atmosphere continuum. There are extensive examples of models that have been developed that simulate these processes in detail; however, one of the major problems that remains is being able to parameterize these models with the necessary information required to allow for their full use across a range of spatial and temporal scales. All models require some type of input, and without the required data it may be necessary to either assume a value for the input data or estimate the required data from some other associated, often more readily available, parameter. The major dilemma that many researchers face in using different models or even testing them outside of the location in which they were developed is finding the required data as inputs into the models. Many of these inputs can't be ignored or eliminated because they are critical variables in the model.

When we consider the data required for effective application of models there is a need for inputs or surrogates for those inputs, enhanced spatial resolution of the input data so the models generate results that represent the spatial scale appropriate for the specific application, and finally, the proper relationship among the parameters so the results accurately represent the process being modeled and are not unrealistic or skewed. These issues do not represent unrealistic expectations for either experimental studies or simulation studies but represent the demands we need to place on how we view the parameters being evaluated. In this chapter, we will explore how energy balance parameters can be assessed for use in simulation models, with examples of energy balance components and how remote sensing data can be used to generate variables that are often simulated by these models as a method of providing an independent comparison of simulated versus estimated parameters.

One of the major difficulties is locating suitable input data for the various meteorological data needed for the model inputs or for parameterization methods. Some worldwide databases are maintained by the Food and Agriculture Organization (FAO) and are available online (www.fao.org/nr/climpag/data_5 en.asp, verified 8 Apr. 2011). This database covers monthly data for 28,100 stations and includes up to 14 observed and computed agroclimatic parameters, including evapotranspiration ( $\mathrm{mm} / \mathrm{month})$, precipitation $(\mathrm{mm} / \mathrm{month})$, sunshine (monthly total), temperature (monthly mean, monthly mean maximum daily, monthly 
mean minimum daily), vapor pressure (mean monthly), wind speed (mean daily, monthly) On this website there are estimation routines to estimate local climate data for use at the monthly time scale. This dataset comprises long-term averages for the period from 1961 to 1990 and time series for rainfall and temperature. These data can be retrieved by geographic area, time period, and parameter and can be downloaded in different formats. The variables available in this database include maximum air temperature, minimum air temperature, mean air temperature, mean nighttime air temperature, mean daytime air temperature, total daily rainfall, dew point temperature, relative humidity, actual vapor pressure, potential evapotranspiration using Penman-Monteith equation, windspeed, global solar radiation, sunshine fraction, and sunshine hours. This is a rich database for the assessment of the meteorological resources.

As a beginning point, it is important to realize that all of these parameters have both a spatial and temporal component. Meteorological variables exhibit well-characterized, defined temporal variation both within a day and across the year. These defined patterns for specific parameters offer potential for the estimation of different values with some degree of confidence; however, the exact magnitude of a given parameter (e.g., temperature) would be dependent on a large number of variables that define the temperature at any given time and location. The spatial aspect of different meteorological variables is much different than the temporal variation. For example, the variation in solar radiation is dependent on cloud cover and frontal passage, which will add a degree of complexity to any attempt to both parameterize and compare modeled and observed results. Throughout this chapter the reader needs to be aware that both spatial and temporal variation exists in all of the different parameters, and there is no single accepted method for characterizing and quantifying either spatial or temporal variation.

There are several challenges that will be covered in this chapter. These include improved spatial and temporal inputs into simulation models, refinement of the methods used to parameterize models, evaluation of the feedback from models when parameters rather than actual data are incorporated into the model, and evaluation of the stability of the predictive methods. These are not impossible challenges and serve to provide a framework for how we should be viewing parameterization methods. These challenges may be addressed from the viewpoint of how energy is exchanged between the surface and the atmosphere and how we could use this framework to develop an understanding of model parameterization. The components within the energy balance approach provide examples of the different parameterization methods. These concepts are not spe- 
cific to any one model but are described to help foster discussion and continued expansion of parameterization algorithms.

\section{Energy Balance Components}

The surface energy balance provides a representation of the energy exchanges and partitioning at the earth's surface and described in a generic form as follows:

$R_{\mathrm{n}}-\mathrm{G}=H+\mathrm{LE}$

where $R_{\mathrm{n}}$ is the net radiation $\left(\mathrm{W} \mathrm{m} \mathrm{m}^{-2}\right), G$ the soil heat flux $\left(\mathrm{W} \mathrm{m}^{-2}\right), H$ the sensible heat flux $\left(\mathrm{W} \mathrm{m}^{-2}\right)$, and LE the latent heat flux $\left(\mathrm{W} \mathrm{m}^{-2}\right)$. This form of the energy balance is a useful approximation of the energy exchanges but is not very useful in simulation models because the processes are not described in sufficient detail in terms of understanding the details that govern the process. For example, $R_{n^{\prime}}$ is more fully described as follows:

$R_{\mathrm{n}}=S_{\mathrm{t}}\left(1-\alpha_{\mathrm{l}}\right)+\mathrm{L}_{\mathrm{d}}-\varepsilon \sigma T_{\mathrm{d}}^{4}$

where $S_{\mathrm{t}}$ is the incoming solar radiation $\left(\mathrm{W} \mathrm{m}^{-2}\right), \alpha_{1}$ the albedo of the surface, $L_{\mathrm{d}}$ the incoming long-wave radiation $\left(\mathrm{W} \mathrm{m}^{-2}\right)$, and $\varepsilon \sigma T_{\mathrm{d}}^{4}$ is the outgoing long-wave radiation as a direct function of surface temperature $\left(T_{s}\right), \varepsilon$ is the emissivity of the surface, and $\sigma$ the Stefan-Boltzmann constant of $5.67 \times 10^{-8} \mathrm{~W} \mathrm{~m}^{-3} \mathrm{~K}^{-4}$. Equation [2] allows for a detailed examination of parameterization of models because there are methods that have been used to estimate these various inputs from more easily derived variables. Likewise, we can expand the $H$ and LE terms into more complex relationships; then there are other possible parameters that can be identified in these relationships. For example, we can expand $H$ into

$H=\rho C_{\mathrm{p}}\left(T_{\mathrm{s}}-T_{\mathrm{a}}\right) R_{\mathrm{ah}}$

where $\rho$ is the density of air $\left(\mathrm{kg} \mathrm{m}^{-3}\right), C_{\mathrm{p}}$ the specific heat of air $\left(\mathrm{J} \mathrm{kg}^{-1}{ }^{\circ} \mathrm{C}^{-1}\right), T_{\mathrm{s}}$ is the surface temperature $\left({ }^{\circ} \mathrm{C}\right), T_{\mathrm{a}}$ the air temperature $\left({ }^{\circ} \mathrm{C}\right)$, and $r_{\mathrm{ah}}$ the aerodynamic resistance $\left(\mathrm{s} \mathrm{m}^{-1}\right)$ for sensible heat transfer. This equation has been used in several different approaches for estimation of sensible heat. There are other aerodynamic forms that are often used to estimate $\mathrm{H}$ as well as the temperature difference method. If we express LE into an expanded form to estimate LE on the basis of surface to air differences then this form is expressed as

$$
\mathrm{LE}=\left(\frac{\rho \lambda m}{P}\right)\left(e_{\mathrm{s}}-e_{\mathrm{a}}\right) /\left(r_{\mathrm{c}}+r_{\mathrm{av}}\right)
$$

where $\lambda$ is the latent heat of vaporization $\left(\mathrm{J} \mathrm{kg}^{-1}\right), m$ the ratio of molecular weight of water vapor to air $(0.622), P$ the barometric pressure $(\mathrm{kPa}), e_{\mathrm{s}}$ the saturation 
vapor pressure $(\mathrm{kPa})$ at the surface temperature, $e_{\mathrm{a}}$ the actual vapor pressure of the overlying air above the canopy, $r_{c}$ the canopy resistance for water vapor transfer $\left(\mathrm{s} \mathrm{m}^{-1}\right)$, and $r_{\mathrm{av}}$ the aerodynamic resistance $\left(\mathrm{s} \mathrm{m}^{-1}\right)$ for water vapor transfer. As with $H$, there are alternative forms of estimating LE. Both Eq. [3] and [4] allow for a direct representation of the surface changes, which makes it easy to visualize how $H$ and LE respond to changes in the surface conditions.

The energy balance equation also allows for a framework to describe different methods of parameterizing models because Eq. [1] can be separated into the components that illustrate different approaches that could be used.

\section{Parameterizing Radiation Models Solar Radiation}

Solar radiation is one of the critical components of the energy balance model and all plant growth models since this provides the energy. Estimation of $S_{t}$ values can be derived starting with fairly basic equations because of the known facts about the geometric relationships between the earth and the sun. These are based on the declination, equation of time, daylength, and daily extraterrestrial radiation values, which can then be used to estimate the instantaneous clear-sky irradiance for both the direct and diffuse components. This approach was provided by Ham (2005) as part of a summary of equations useful in micrometeorology. These approaches provide a very good estimation process for solar radiation in the direct and diffuse components under clear sky conditions. Clouds present a unique challenge because of their variability in thickness, time of day, and type. There have been several methods proposed to estimate $S_{t}$ for cloudy conditions using empirical relationships (e.g., Bristow and Campbell, 1984). Bristow and Campbell (1984) used a relationship based on the difference between the daily maximum and minimum temperatures $(\Delta T)$ described as

$S_{\mathrm{t}}=a\left[1-\exp \left(-b_{\Delta} T^{2}\right)\right] S_{\mathrm{e}}$

where $S_{\mathrm{e}}$ is the extraterrestrial solar radiation $\left(\mathrm{W} \mathrm{m}^{-2}\right)$ and $a, b$, and $c$ are empirically derived values. There are 16 different forms of empirical relationships, as shown in Table 9-1. These empirical models represent a range of different variables and equation forms. The advantage of these types of models is the use of more commonly available meteorological variables compared to a relatively sparse network of solar radiation sensors. Liu et al. (2009) compared these different models in China and found the Bristow and Campbell (1984) model correlated significantly with the common meteorological parameters. There is still a need for calibration of these models, but in their comparison this model was the most 
Table 9-1. Empirical relationships for estimating solar radiations based on meteorological variables.†

\begin{tabular}{|c|c|c|}
\hline Empirical relationship & Estimated parameters & Reference \\
\hline$S_{t}=a\left[1-\exp \left(-b \Delta T^{\tau}\right)\right] S_{e}$ & $a, b, c$ & Bristow and Campbell (1984) \\
\hline$S_{\mathrm{t}}=a \sqrt{\Delta T} S_{\mathrm{e}}$ & $a$ & Hargreaves (1981) \\
\hline$S_{\mathrm{t}}=a \Delta T^{b}\left(1+c P+d P^{2}\right) S_{\mathrm{e}}$ & $a, b, c, d$ & DeJong and Stewart (1993) \\
\hline$S_{\mathrm{t}}=a\left[1-\exp \left(-b \frac{\Delta T^{c}}{\Delta T^{b}}\right)\right] S_{\mathrm{e}}$ & $a, b, c$ & Donatelli and Campbell (1998) \\
\hline $\begin{array}{l}\left.S_{\mathrm{t}}=a\left\{1-\exp \left[-b\left(T_{\text {avg }}\right) \Delta T^{t}\right)\right]\right\} S_{\mathrm{e}} \\
f\left(T_{\text {avg }}\right)=0.017 \exp \left[\exp \left(-0.053 T_{\text {avg }} \Delta T^{c}\right)\right]\end{array}$ & $a, b, c$ & Donatelli and Campbell (1998) \\
\hline $\begin{array}{l}S_{\mathrm{t}}=a\left\{1-\exp \left[-b f\left(T_{\text {avg }}\right) \Delta T^{2} g\left(T_{\min }\right)\right]\right\} S_{\mathrm{e}} \\
g\left(T_{\min }\right)=\exp \left(T_{\min } / T_{\mathrm{nc}}\right)\end{array}$ & $a, b, T_{\mathrm{nc}}$ & Donatelli and Campbell (1998) \\
\hline$S_{\mathrm{t}}=a \sqrt{\Delta T} S_{\mathrm{e}}+b$ & $a, b$ & Hunt et al. (1998) \\
\hline$S_{\mathrm{t}}=a \sqrt{\Delta T} S_{\mathrm{e}}+b T_{\max }+c P+d P^{2}+e$ & $a, b, c, d, e$ & Hunt et al. (1998) \\
\hline$S_{\mathrm{t}}=a\left[1-\exp \left(-b \frac{\Delta T^{c}}{S_{\mathrm{e}}}\right)\right] S_{\mathrm{e}}$ & $a, b, c$ & Goodin et al. (1999) \\
\hline$S_{\mathrm{t}}=0.75\left[1-\exp \left(-b \Delta T^{2}\right)\right] S_{\mathrm{e}}$ & $b$ & Meza and Varas (2000) \\
\hline$S_{\mathrm{t}}=0.75\left[1-\exp \left(-b \frac{\Delta T^{2}}{S_{\mathrm{e}}}\right)\right] S_{\mathrm{e}}$ & $b$ & Weiss et al. (2001) \\
\hline$S_{\mathrm{t}}=0.75\left\{1-\exp \left[-b f\left(T_{\text {avg }}\right) \Delta T^{2}\right]\right\} S_{\mathrm{e}}$ & $b$ & Weiss et al. (2001) \\
\hline$S_{\mathrm{t}}=a\left(1+2.7 \times 10^{-5} \mathrm{Alt}\right) \sqrt{\Delta T} S_{\mathrm{e}}$ & $a$ & Annandale et al. (2002) \\
\hline$S_{\mathrm{t}}=(a+\sqrt{\Delta T}+b) S_{\mathrm{e}}$ & $a, b$ & Chen et al. (2004) \\
\hline$S_{\mathrm{t}}=a\left\{1-\exp \left[-b f\left(T_{\mathrm{avg}}\right) \Delta T^{2} g\left(T_{\min }\right)\right]\right\} S_{\mathrm{e}}$ & $b, T_{\mathrm{nc}}$ & Abraha and Savage (2008) \\
\hline$S_{\mathrm{t}}=0.75\left[1-\exp \left(-b \frac{\Delta T^{c}}{\Delta T_{m}}\right)\right] S_{\mathrm{e}}$ & $b, c$ & Abraha and Savage (2008) \\
\hline
\end{tabular}

$\dagger \Delta T$, diurnal range of temperature $\left({ }^{\circ} \mathrm{C}\right) ; T_{\text {max }}$, daily maximum temperature $\left({ }^{\circ} \mathrm{C}\right) ; T_{\text {min }}$, daily minimum temperature $\left({ }^{\circ} \mathrm{C}\right) ; T_{\text {avg }}\left(T_{\max }+T_{\min }\right) / 2 ; \Delta T_{\mathrm{m}^{\prime}}$ monthly mean temperature $\left({ }^{\circ} \mathrm{C}\right) ; S_{\mathrm{t}^{\prime}}$, solar radiation $\left(\mathrm{W} \mathrm{m}^{-2}\right) ; S_{\mathrm{e}^{\prime}}$ extraterrestrial radiation $\left(\mathrm{W} \mathrm{m}^{-2}\right) ; A$ itt, altitude $(\mathrm{m}) ; P$, precipitation $(\mathrm{mm})$.

stable over the different times. These types of models provide valid methods for the estimation of solar radiation, and many have been developed specifically for use with crop simulation models. There needs to be an expansion of the comparison of these models over wider spatial areas and times of year to evaluate the robustness of the relationships. 


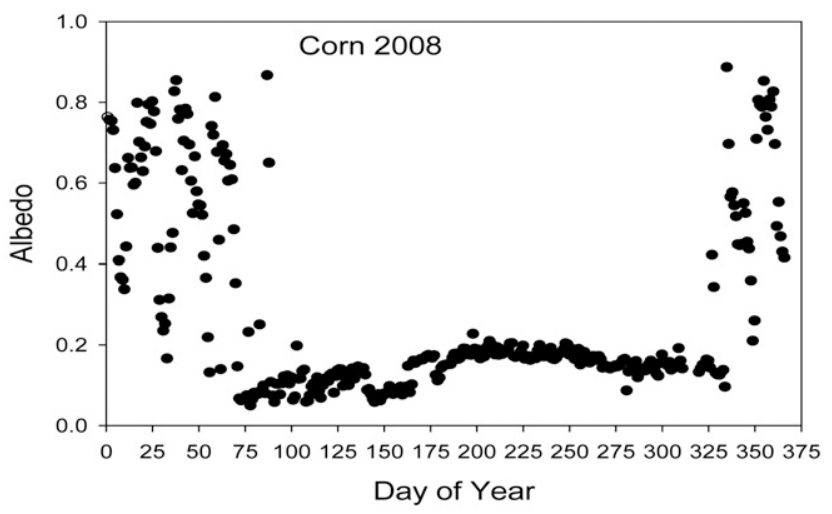

Fig. 9-1. Albedo changes during the course of a year for a corn field in central lowa.

\section{Albedo}

Estimation of albedo is necessary if the energy balance is based on the radiation components and not a direct measure of net radiation. Albedo values for a cropped surface range from 0.22 to 0.32 over the course of a growing season and often a mean value of 0.27 is selected out of convenience. Albedo values vary as a function of soil, with light colored soils having albedo values near 0.30 and darker soils values near 0.15 or less. An example of the changes in albedo throughout the course of a year over a corn (Zea mays L.) field in central Iowa is shown in Fig. 9-1. Albedo values are very high during the winter when there is snow cover and change rapidly as the snow melts between snowfall events; during the early spring when there is no crop canopy present the albedo values are near 0.10 . Albedo values increase to 0.2 as the canopy develops and then decrease again in the fall as the crop is harvested and the soil is tilled. Each year has different snowfall amounts, which affects the winter albedo, but the trends during the spring to fall are consistent in this area, with increasing albedo values because of the dark soils. In light colored soils, there would be a reversal of these patterns during the course of the year.

Wright (1982) proposed a fairly simple empirical relationship to predict albedo for a crop as a function of day of year (DOY):

$$
\alpha=0.29+0.06 \sin \left(\frac{\mathrm{DOY}+96}{57.3}\right)
$$

This is a simple relationship for an alfalfa (Medicago sativa L.) crop and is given as an illustration of how $\alpha$ could be quantified for a surface from measurements. 
Albedo over a surface varies throughout the year, and in areas with snow cover the annual range in values can be between 0.2 and 0.8 . Evaluation of different methods of estimating albedo would provide a valuable input into crop simulation and energy balance models.

Methods are available to obtain albedo from remote sensing measurements, and Carrer et al. (2008) showed that these provided reliable estimates of the spatial variation in albedo and suitable for weather forecasting. The errors in these models would be on the same order of magnitude as other measurements, with errors of less than $5 \%$ in the reported values. Reflectivity of a surface is easily obtained with remote sensing data, and for many of the studies on crop simulation modeling or energy balance model that represents a field scale, the use of high resolution models would be necessary. The same principles would apply across all of the different scales in terms of the types of algorithms to estimate albedo.

\section{Long-Wave Radiation}

Long-wave radiation is a large component of the total radiation budget and a factor that is often overlooked as to its importance in energy exchanges. As shown in Eq. [2] there are two components in the long-wave portion of net radiation. There are methods available to estimate these fractions of the net radiation balance.

\section{Incoming}

The incoming long-wave radiation is a function of the emission from the atmosphere. There have been several attempts to relate incoming long-wave to temperature and humidity in methods similar to those discussed for solar radiation. These different methods were summarized in Hatfield et al. (1983) and are shown in Table 9-2. The comparison of these models over several locations in the United States revealed that that original Brunt formula and the Brutsaert model with a coefficient of 0.575 predicted incoming long-wave radiation with errors less than $5 \%$. These models didn't include a local correction for water vapor, which further increases the simplicity of the model.

\section{Outgoing}

The emission of long-wave radiation is a simple function of temperature as shown in Eq. [2], and $\sigma$ is the Stefan-Boltzmann constant and $\varepsilon$ the emissivity of the surface. To estimate the outgoing long-wave radiation requires a measure of the surface temperature or the assumption that the near surface air temperature and the surface temperature are equal or nearly equal. This is not often the case; however, it does provide a reasonable approximation. The other variable term is emissivity, which for most natural surfaces ranges from 0.92 to 0.98 . One could assume a con- 
Table 9-2. Empirical long-wave radiation estimation methods based on meteorological data.

$\begin{array}{ll}\text { Empirical relationship } & \text { Reference } \\ L_{d}=0.51+0.66 e_{o}^{1 / 2} & \text { Brunt (1932) } \\ L_{d}=0.92 \times 10^{-5} e_{o}^{2} & \text { Swinbank (1963) } \\ L_{d}=1-0.261\left[-7.704\left(273-T_{o}\right)^{2}\right] & \text { Idso and Jackson (1969) } \\ L_{d}=0.533 e_{o}^{1 / 7} & \text { Brutsaert (1975) } \\ L_{d}=0.575 e_{o}^{1 / 7} & \text { Idso (1981) } \\ L_{d}=0.179 e_{0}^{1 / 7} \exp \left(350 / T_{0}\right) & \text { Idso (1981) } \\ L_{d}=0.70+5.95 \times 10^{-5} e_{o} \exp \left(1500 / T_{0}\right) & \text { Idso (1981) }\end{array}$

$e_{\mathrm{o}}$, water vapor pressure (millibars); $T_{\mathrm{o}}$, air temperature $(\mathrm{K})$.

stant value of 0.95 or 0.96 and not create a large error in the estimation of long-wave radiation. For crop canopies the range of emissivity values is between 0.97 and 0.99 , which further reduces the potential error in the ongoing long-wave calculation.

\section{Soil Heat Flux}

One of the more difficult parameters to obtain in the energy balance is soil heat flux, $G$ (Eq. [1]). Values for $G$ can be estimated in simulation models by using the change in spoil temperature with time and depth and estimating the amount of energy required to cause the change in soil temperature assuming the water content, heat capacity of the soil, and bulk density of the soil. These are complex equations that require several inputs, and the approach for the Root Zone Water Quality Model (RZWQM) was described by Flerchinger et al. (2000). Throughout the growing season, $G$ can vary from nearly $30 \%$ of net radiation to less than $5 \%$ under a dense canopy. Because soil heat flux is related to the development of the plant canopy in annual crops, there have been several approaches to estimate values for $G$. Clothier et al. (1986) observed during the regrowth cycles in alfalfa that and found that the ratio of near-infrared to red (NIR/R) was a linearly decreasing function relative to $G$ values. They suggested that this ratio could be used to accurately estimate $G$ in alfalfa crops. Kustas and Daughtry (1990) found that the NIR/R ratio worked equally well in cotton (Gossypium hirsutum L.) canopies compared to alfalfa canopies and the standard error of estimate was 0.03 in the ratio of $G / R_{n}$. This would be acceptable in energy balance studies. The use of these simple ratios to estimate values for $G$ would be useful in crop simulation models since values of $G$ are rarely observed except in detailed energy balance studies. Bastiaanssen et al. (1998) derived all of the components of the surface energy balance to estimate a spatially distributed surface energy balance and found they could reliably use the ratio of $G / R_{n}$ derived from remotely sensed data for these largescale models. Values for $\mathrm{G}$ are relatively small compared to the other components, 
but not accounting for these values will lead to errors in the energy balance, and these methods produce reliable estimation methods.

Estimation of $G$ provides an initial step in the estimation of soil temperature profiles within the soil. Soil temperature is relatively well behaved as a process and has a defined sinusoidal pattern throughout the day. Soil temperature has been extensively studied, and there have been several reports written on the methods to estimate soil temperature from a combination of $G$, soil properties, and water content. These were summarized by Novak (2005), who showed how soil temperatures could be estimated from different approaches. Many of these methods are incorporated into simulation models where soil temperatures are required as part of the overall simulation scheme.

\section{Overall Radiation Balance}

As described above, the balance of radiation to form net radiation (Eq. [1]) at the surface of the earth can be estimated by several methods. These have been developed as a function of observable meteorological parameters. Air temperature has been used most often because of the extensive nature of these data. Most of the incoming solar radiation models that use some sort of air temperature relationship (Table 9-1) have been shown to be fairly robust for use across a wide range of conditions. Similarly, there are temperature-based methods for incoming long-wave radiation (Table 9-2), and one of the most robust ones is also one of the original relationships developed (Brunt, 1932). The outgoing terms can be estimated using empirical relationships that describe the surface. Of these, albedo shows the largest temporal change for crop canopies because of the growth and senescence of the crop and is where efforts should be placed in improving these relationships.

The alternative to estimating these parameters is to obtain direct measurements as inputs. Both methods have errors associated with them. The errors in different measurement methods have been discussed in a series of chapters in a monograph edited by Hatfield and Baker (2005). Empirical equations extracted from the literature don't often report the associated uncertainty with the different models, and this information would be invaluable to help guide the users of these relationships. On the other hand, there is very little uncertainty assessment provided on observed data, and the user has to assume that every precaution was taken to ensure the highest quality of data possible.

\section{Refinement of Crop Model Parameters}

Crop growth models and even energy balance models often generate canopy characteristics that represent different aspects of crop growth to estimate 


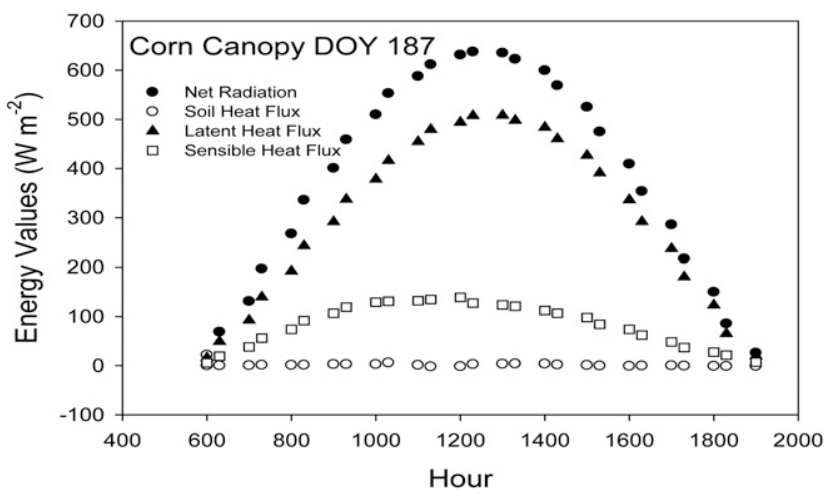

Fig. 9-2. Partitioning of the energy balance throughout the day for a corn canopy in central lowa.

evapotranspiration or sensible heat exchange. Crop growth parameters change throughout the growing season, and these changes affect the overall energy balance. For example, as the crop develops and as ground cover increases there is a shift in the energy balance toward less soil heat flux and increased latent heat flux. The partitioning of these components throughout the day is shown in Fig. 9-2. On this day, with a leaf area index of 5 there was a very small amount of energy used for soil heat flux, and the canopy had an adequate soil water supply so that latent heat flux was the largest component, followed by sensible heat flux. With limited soil water for evapotranspiration, LE would be reduced and $H$ would increase. The seasonal changes in the energy balance are affected by parameters associated with crop growth, and crop simulation models estimate these values. However, the values for these parameters are not always available for many different fields and at a fine temporal resolution expect in very intense field experiments. It is desirable to have estimates of these values to compare model performance and their capability of predicting crop growth.

Characteristics such as leaf area, biomass, ground cover, or even crop residue amounts can be derived primarily from remote sensing methods to provide a feedback to models for crop growth or a direct inputs into some models. Maas (1988) was one of the first to show that is was possible to use this type of approach to improve the performance of crop yield prediction. In his approach there was an estimate of leaf area index (LAI) from remote sensing which was compared to the modeled result and provided feedback to the model as a sort of mid-course correction. This improved the performance of the crop simulation models (Maas, 1993). 


\section{Leaf Area Index}

Leaf area index can be estimated through many different remote sensing approaches. These have been summarized in various reports (Hatfield et al., 2008), and a brief summary of the literature developed during the past $20 \mathrm{yr}$ still remains useful and critical today as methods to estimate LAI. Zheng and Moskal (2009) reviewed the approaches that can be used at the landscape and regional scales and concluded that incorporation of short-wave infrared (SWIR) wavebands provided an enhancement to the visible and near-infrared wavebands typically used in calculating most vegetative indices.

Leaf area index has been used to assess the ability of a plant to intercept light, and LAI is used as a critical calculation in crop growth models. The NIR/R ratio was found to be highly correlated with green LAI. However, there was a different form of the relationship of LAI $=a+b \mathrm{NIR} / \mathrm{R}$ for the growth and senescence portions of the growth cycle. Leaf area estimates for different crops across locations have been summarized by Wiegand and Hatfield (1988) and Wiegand et al. (1990). The LAI for wheat (Triticum aestivum L.) was best estimated by the NIR/R ratio or the TSAVI index using the linear relationships LAI $=a+b \mathrm{NIR} / \mathrm{R}$ and $\mathrm{LAI}=a+b$ TSVAI. Thus, estimates of LAI are possible with simple linear models using NIR/R reflectance. However, there is improvement when the same parameters are used but in a different form for different growth stages, with greatly improved sensitivity. These relationships are valid across a number of crops and agronomic practices within and among locations. To be useful for standard agronomic practices these relationships need to be calibrated for a specific crop. The multi-site comparisons for corn, wheat, and grain sorghum [Sorghum bicolor (L.) Moench] provide a degree of confidence that remote sensing measures can be adequately used to estimate LAI.

There is a also relationship between LAI and light interception in plant canopies. One approach that has been proposed for estimating LAI is based on the relationships between fractional cover, $f_{\mathrm{C}}$ and LAI using a relatively simple exponential relationship (Choudhury, 1987):

$f_{\mathrm{C}}=1-\exp (-\beta \mathrm{LAI})$

where $\beta$ is a function of the leaf angle distribution. He estimated $\beta$ as 0.67 from an average of 18 broadleaf and grass crops. This method, although robust, has not been applied as often as NIR/R ratios because the first step in this method is to obtain an estimate of ground cover or fractional cover and then incorporated into Eq. [7]. The multiple steps for this approach have contributed to the more widespread use of the simple regression models between vegetation indexes and LAI. 


\section{Crop Biomass}

Crop biomass represents the total aboveground accumulation of plant material and is a measure of net primary productivity of crop canopies. Biomass directly affects the energy balance because of the associated relationship between increasing biomass and ground cover. Remote sensing has been used to estimate dry matter accumulation or biomass estimation through a combination of NIR and red wavebands. These empirical fits have plant specific relationships because of the difference in NIR reflectance among species; therefore, this approach requires calibration for each crop and soil combination. There is a stronger relationship to green biomass with the NIR/R combinations than to total biomass, which includes stems, branches, and other non-green material.

Other approaches to estimating crop biomass have been to use a conversion factor of intercepted solar radiation to crop biomass using the following form of the relationship:

Biomass $=\int$ PAR fIPAR RUE $\Delta t$

where PAR is the incident photosynthetic active radiation, fIPAR the fraction of intercepted PAR by the canopy, RUE the radiation use efficiency for conversion of PAR to dry biomass, and $\Delta t$ the time interval. The estimation of the intercepted values of PAR has taken on many different forms for this approach.

\section{Intercepted Solar Radiation}

Estimation of crop biomass is often based on intercepted light by crop canopies and is a critical component in plant growth models. Estimation of light interception by canopies from remotely sensed data would greatly aid in comparing management systems and also in the evaluation of crop growth models. Intercepted light by a crop canopy can be related to the accumulation of biomass and harvestable grain yield. Daily estimates of intercepted light can be obtained from extrapolation of observations of the normalized difference vegetation index (NDVI) combined with daily total PAR obtained from a nearby meteorological station. It is possible to directly compare the performance of different cropping systems using this type of approach with confidence in the results. Observations collected over a wide range of crops and growing conditions suggest that LAI is best obtained from NIR/R ratios, while incident photosynthetic active radiation is best determined from NDVI obtained in remote sensing. These relationships have been developed by several different researchers (Table 9-3) and were recently summarized by Hatfield et al. (2008). Hatfield and Prueger (2010) evaluated the different vegetative indices for corn, soybean [Glycine $\max$ (L.) Merr.], wheat, and canola (Brassica napus L. var. napus) 
Table 9-3. Summary of selected vegetation indices, wavebands, applications, and citations.†

\begin{tabular}{|c|c|c|c|}
\hline Index & Relationship & Application & Reference \\
\hline Difference & $R_{800}-R_{680}$ & Biomass & Jordan (1969) \\
\hline Difference & $R_{800}-R_{550}$ & Biomass & Buschmann and Nagel (1993) \\
\hline Ratio & $R_{\mathrm{NIR}} / R_{\mathrm{red}}$ & Biomass, LAI & Birth and McVey (1968) \\
\hline $\begin{array}{l}\text { Perpendicular } \\
\text { vegetative } \\
\text { index }\end{array}$ & $\left(R_{\mathrm{NIR}}-R_{\mathrm{red}}-b\right) /\left(1+a^{2}\right)^{1 / 2}$ & LAI & $\begin{array}{l}\text { Richardson and Wiegand } \\
\text { (1977) }\end{array}$ \\
\hline $\begin{array}{l}\text { Normalized } \\
\text { difference } \\
\text { vegetative } \\
\text { index }\end{array}$ & $\left(R_{\mathrm{NIR}}-R_{\mathrm{red}}\right) /\left(R_{\mathrm{NIR}}+R_{\mathrm{red}}\right)$ & Intercepted PAR & Deering (1978) \\
\hline $\begin{array}{l}\text { Soil adjusted } \\
\text { vegetative } \\
\text { index }\end{array}$ & $\left(R_{\mathrm{NIR}}-R_{\mathrm{red}}\right)(1+L) /\left(R_{\mathrm{NIR}}+R_{\mathrm{red}}+L\right)$ & LAI & Huete (1988) \\
\hline $\begin{array}{l}\text { Transformed } \\
\text { soil adjusted } \\
\text { vegetative } \\
\text { index }\end{array}$ & $a\left(R_{\mathrm{NIR}}-a R_{\mathrm{red}}-b\right) /\left(R_{\mathrm{red}}+a R_{\mathrm{NIR}}-a b\right)$ & LAI, biomass & Baret et al. (1989) \\
\hline
\end{tabular}

$+R_{550}, R_{680}$, and $R_{800}$, reflectance at the 550 (green), 680 (red), and 800 (near-infrared) $\mathrm{nm}$ wavelengths, respectively; $R_{\mathrm{NR}}$, reflectance in near-infrared wavebands; $R_{\text {red }}$, reflectance in red wavebands; $a, b$, and $L$, coefficients based on empirical fits; LAI, leaf area index; PAR, photosynthetic active radiation.

to evaluate the errors in using these vegetative indices and found that properly calibrated models estimated leaf area or biomass with the same error as direct plant sampling. The use of NDVI to obtain intercepted light was shown to have an uncertainty of $\pm 10 \%$, which is comparable to variation in values obtained from radiometers placed above and below the canopy.

One of the applications of intercepted light is determination of the rate of senescence of crop canopies. The rate of change in the NDVI can be utilized as a tool to examine how quickly plants are losing their physiological functions at the end of the growing season. This approach offers potential to determine if the rates of changes are different than expected and may indicate if there are some factors causing premature loss of green leaves in the canopy. This type of approach is often used for visual determination of premature changes in the canopy and could be easily determined from remote sensing platforms.

One component of biomass accumulation is the gross primary productivity (GPP). Gitelson et al. (2006) found that GPP relates closely to total chlorophyll content in maize and soybean. The relationship algorithm for GPP estimation provided accurate estimates of midday GPP in both crops under rainfed and irrigated conditions. This approach has not been rigorously evaluated but offers potential to improve biomass estimates. 


\section{Crop Ground Cover}

One of the components often evaluated for agricultural applications is the amount of ground covered by the crop canopy, expressed as the fraction of ground area covered by the projection of standing leaf and stem area onto the ground surface. Changes in ground cover are often indicative of the health of the crop. Determination of ground cover provides a linkage between the growth of the crop and water use patterns of the crop since many evapotranspiration (ET) models use crop cover to relate Potential ET to actual ET.

Maas (1988) proposed a method of estimating canopy ground cover in cotton that combined the overall reflectance of the scene and the individual reflectance values from the soil and the crop. He developed the following model for ground cover:

$\mathrm{GC}=\left(R_{\text {scene }}-R_{\text {soil }}\right) /\left(R_{\text {canopy }}-R_{\text {soil }}\right)$

where GC is the fraction of ground cover, $R_{\text {scene }}$ is the scene reflectance, $R_{\text {soil }}$ is the soil reflectance, and $R_{\text {canopy }}$ is the canopy reflectance. By rearranging Eq. [9], the scene reflectance is given as

$R_{\text {scene }}=R_{\text {canopy }} \mathrm{GC}+R_{\text {soil }}(1-\mathrm{GC})$

He used reflectance values from either red $(0.6-0.7 \mu \mathrm{m})$ or NIR $(0.8-0.9 \mu \mathrm{m})$ for these relationships and found that either waveband could be used. This method of estimating ground cover was independent of location and year. This method was not dependent on empirical fits of the vegetation indexes with plant parameters. Estimation of ground cover via remote sensing has proven to be fairly simple and not subject to problems associated with LAI or incident photosynthetic active radiation. The error in estimates of ground cover using these approaches has been on the order of $\pm 5 \%$. This level of error is acceptable for agricultural applications that require ground cover estimates. In a recent study by Rajan and Maas (2009), they used the photosynthetic vegetation index (PVI) for the canopy compared to a full canopy area $\left(\mathrm{PVI}_{\mathrm{FC}}\right.$ for each pixel being evaluated to derive the following relationship for ground cover (GC)

$\mathrm{GC}=\mathrm{PVI} / \mathrm{PVI} \mathrm{FC}$

They found they could estimate GC with an accuracy of $3 \%$ of the true values, which would be acceptable for almost all applications. Ground cover has been used in the estimation of crop growth (Boissard et al., 1992; Asrar et al., 1992). In a recent analysis, Ritchie et al. (2010) used green/red ratios obtained from digital cameras to estimate ground cover with a correlation of $\left(r^{2}=0.86\right)$. They found the effective range of ground cover estimates using this method was between 0.2 to 
0.8 and was less sensitive at the lower values of ground cover. This would present a problem in the use of this index because the impact of ground cover is most significant at the lower values.

The use of remote sensing methods to derive the above crop growth characteristics either as direct input into large area models or as comparison values for feedback to evaluate and refine model parameters provides a method of comparing across scales. Doraiswamy et al. (2003) provided one of the earlier examples of blending remotely sensed data with crop yield models to estimate crop yields at the state level. There continues to be refinement of these types of approaches for crop yield estimation, and most of these use some combination of the methods described in the previous sections.

\section{Measurement Methods: Comparing Models with Measured Variables}

It is beyond the scope of this chapter to cover all of the specific details about the measurement of the different parameters required by models or generated by models that need to be compared in terms of actual versus modeled output. The collection and assembly of high quality data over long periods of time is a valuable resource for the modeling community, and the development of catalogs of available data would be a great asset. Modelers are urged to evaluate the uncertainty associated with specific variables required in the different models, and although sensitivity analyses on model inputs are often conducted, these are not always linked with the measurement errors in a particular measurement. Meek and Hatfield (1994) developed a systematic approach for data quality checking for meteorological station data to help improve the reliability of different data collected from these stations. One of the problems that exists within meteorological datasets is the evaluation of the data quality. This has become an increased emphasis over the past few years, which makes it difficult at times to fully utilize data without a thorough screening before it is used. Another type of comparison that has become more common is to conduct intercomparisons of multiple instruments as a method of being able to assess the differences that could be detected among instruments when deployed in the field. This method was described by Meek et al. (2005) for a series of eddy covariance equipment. They found they could compare multiple instruments, and detectable differences were then used to evaluate differences among locations within a series of watershed scale studies. These types of rigorous intercomparisons may be more valuable to help link observations with simulation models because of the ability to provide an analysis of the instrumentation variance and systematic biases. 
Measurement of different variables required as input into simulation models also includes the instrumentation accuracy. There is not a uniform summary of the accuracy for different classes of instrumentation because of the deployment of the instrument, the efforts taken to ensure a high quality data set, the screening of the data for any potential problems, and differences among instruments. The reader is cautioned to be aware of these issues and to work closely with individuals collecting data to understand the complexities in the observational data. A summary and comparison of methods for measuring the parameters discussed in this chapter are included in the monograph by Hatfield and Baker (2005). Measurement methods need to be robust and evaluated for their accuracy and reliability across a number of crops. One thing that would help the modeling community would be to provide more assessment of the variation associated with the values reported in research papers. Then it would be easier to determine if the model predictions are within the variance of the measured results.

\section{Challenges and Emerging Approaches}

Parameterizing models requires inputs that may not be readily available from routine sources or may include derived parameters that are difficult to measure directly. The most common approaches to derive the inputs into the energy balance models begin with solar and long-wave radiation, and these have been done with various relationships with temperature. Some of the approaches are locally calibrated and developed and have a limited range of application. Others, however, tend to have a wider range of application. The challenge for the modeling community is to evaluate thoroughly the algorithm against measured data for a particular site. There is no universal method of deriving some of these parameters and perhaps even less attention is given to evaluating the performance of many of these algorithms across larger areas or different applications. The paper by Liu et al. (2009) is one of the more recent comparisons of a number of the solar radiation models. There should be a greater effort to provide these comparisons across a wider range of environments as a service to the modeling community. The approaches currently available help to provide the modeling community with more rigorous analyses of many of these estimation methods. Applying this approach to all of the different modeling components could enhance the reliability and spatial extent of many of the modeling approaches.

There are some emerging challenges that provide some opportunities. One example is the recent effort by Perez et al. (2009) to classify $\mathrm{CO}_{2}$ concentrations using meteorological classification approaches. With the increasing interest in $\mathrm{C}$ dynamics of the atmosphere and the exchange of $\mathrm{CO}_{2}$ between the surface and 
the atmosphere this type of approach may provide some insights into the overall model performance or dynamics of the system. The use of Doppler radar to provide estimates of the spatial variation of rainfall provides a distinct advantage over current rain-gauge networks. These efforts will continue to improve as the capabilities and calibration of the Doppler systems advance with technological innovations. Remote sensing of surface soil moisture with microwave methods will increase as satellite systems that carry these instruments become capable of providing more continuous coverage, similarly to the way in which we obtain cloud cover estimates from weather satellites today. All of these offer the potential to improve crop simulation modeling.

The major challenge will be the continued dialog between the modeling community and the measurement community to help improve the parameterization algorithms. Enhancement of models will come with improved inputs and more reliable data sources. Understanding these needs will help to advance modeling efforts and to acquire even more reliable input data. One component of that effort could be the development of a website or location where parameterization routines are posted along with their validation and calibration data sources. With time as these are used the performance evaluations could be made available as well. In the long term this would benefit all of science.

\section{References}

Abraha, M.G., and M.J. Savage. 2008. Comparison of estimates of daily solar radiation from air temperature range for application in crop simulations. Agric. For. Meteorol. 148:401-416Annandale, J.G., N.Z. Jovanic, N. Benade, and R.G. Allen. 2002. Software for missing data error analysis of Penman-Monteith reference evapotranspiration. Irrig. Sci. 21:57-67.

Asrar, G., R.B. Myneni, and B.J. Choudhury. 1992. Spatial heterogeneity in vegetation canopies and remote sensing of absorbed photosynthetically active radiation: A modeling study. Remote Sens. Environ. 41:85-103.

Baret, F., G. Guyot, and D.J. Major. 1989. TSAVI: A vegetation index which minimizes soil brightness effects on LAI and APAR estimation. Proc. IGARRS 12th Canadian Symposium on Remote Sensing, Vancouver, Canada. 3:1355-1358.

Bastiaanssen, W.G.M., M. Menenti, R.A. Feddes, and A.A.M. Holtslag. 1998. A remote sensing surface energy balance algorithm for land (SEBAL). 1. Formulation. J. Hydrol. 212-213:198-212.

Birth, G.S., and G. McVey. 1968. Measuring the color of growing turf with a reflectance spectrophotometer. Agron. J. 60:640-643.

Boissard, P., J.-G. Pointel, and J. Tranchefort. 1992. Estimation of the ground cover ratio of wheat using radiometry. Int. J. Remote Sens. 13:1681-1692.

Bristow, K.L., and G.S. Campbell. 1984. On the relationship between incoming solar radiation and daily maximum and minimum temperature. Agric. For. Meteorol. 31:159-166.

Brunt, D. 1932. Notes on radiation in the atmosphere. Q. J. R. Meteorol. Soc. 58:389-418.

Brutsaert, W. 1975. On a derivable formula for long-wave radiation from clear skies. Water Resour. Res. 11:742-744.

Buschmann, C., and E. Nagel. 1993. In vivo spectroscopy and internal optics of leaves as basis for remote sensing of vegetation. Int. J. Remote Sens. 14:711-722.

Carrer, D., B. Geiger, J.-L. Roujean, O. Hautecoeur, J. Cedilnik, J.-F. Mahfouf, C. Meurey, and O. Franchisteguy. 2008. Land surface albedo from MSG/SEVIRI: Retrieval method, validation, and application for weather forecast. Trans. Geosci. Remote Sens. 47:3841-3856. 
Chen, R.S., K. Ersi, J.P. Yang, S.H. Lu, and W.Z. Zhao. 2004. Validation of five global radiation models with measured daily data in China. Energy Conserv. Manage. 45:1759-1769.

Choudhury, B.J. 1987. Relationships between vegetation indices, radiation absorption, and net photosynthesis evaluated by a sensitivity analysis. Remote Sens. Environ. 22:209-233.

Clothier, B.E., K.L. Clawson, P.J. Pinter, Jr., M.S. Moran, R.J. Reginato, and R.D. Jackson. 1986. Estimation of soil heat flux from net radiation during the growth of alfalfa. Agric. For. Meteorol. 37:319-329.

Deering, D.W. 1978. Rangeland reflectance characteristics measured by aircraft and spacecraft sensors. Ph.D. diss. Texas A\&M University, College Station, TX.

DeJong, R., and D.W. Stewart. 1993. Estimating global solar radiation from common meteorological observations in western Canada. Can. J. Plant Sci. 73:509-518.

Donatelli, M., and G.S. Campbell. 1998. A simple model to estimate global solar radiation. p. 133134. In Proc. ESA Congr. 5th Nitra Slovak Republic, 28 June- 2 July 1998. The Slovak Agric. Univ. Nitra, Slovak Republic.

Doraiswamy, P.C., S. Moulin, P.W. Cook, and A. Stern. 2003. Crop yield assessment from remote sensing. Photogramm. Eng. Remote Sens. 69:665-674.

Flerchinger, G.N., R.M. Aiken, K.W. Rojas, L.R. Ahuja, K.E. Johnson, and C.V. Alonso. 2000. Soil heat transport, soil freezing and snowpack conditions. p. 281-314. In L.J. Ahjua et al. (ed.) Root Zone Water Quality Model: Modeling management effects on water quality and crop production. Water Resources Publ., Highlands Ranch, CO.

Gitelson, A.A., A. Viña, S.B. Verma, D.C. Rundquist, T.J. Arkebauer, G. Keydan, B. leavitt, V. Ciganda, G.G. Burba, and A.E. Suyker. 2006. Relationship between gross primary production and chlorophyll content in crops: Implications for the synoptic monitoring of vegetation productivity. J. Geophys. Res. 111:D08S11, doi:10.1029/2005JD006017.

Ham, J.M. 2005. Useful equations and tables in micrometeorology. p. 533-560. In L.J. Hatfield and J.M. Baker (ed.) Micrometeorology in agricultural systems. Agron. Monogr. 47. ASA, CSSA, and SSSA, Madison, WI.

Hargreaves, G.H. 1981. Responding to tropical climates. p. 29-32. In The 1980-81 food and climate review. The Food and Climate Forum, Aspen Institute for Humanistic Studies, Boulder, CO.

Hatfield, J.L., and J.M. Baker. 2005. Micrometeorology in agricultural systems. Agron. Monogr. 47. ASA, CSSA, and SSSA, Madison, WI.

Hatfield, J.L., A.A. Gitelson, J.S. Schepers, and C.L. Walthall. 2008. Application of spectral remote sensing for agronomic decisions. Agron. J. 100:S-117-S-131.

Hatfield, J.L., and J.H. Prueger. 2010. Value of using different vegetative indices to quantify agricultural crop characteristics at different growth stages under varying management practices. Remote Sens. 2:562-578, doi:10.3390/rs2020562.

Hatfield, J.L., R.J. Reginato, and S.B. Idso. 1983. Comparison of long-wave radiation calculation methods over the United States. Water Resour. Res. 19:285-288.

Huete, A.R. 1988. A soil-adjusted vegetative index (SAVI). Remote Sens. Environ. 16(25):295-309.

Hunt, L.A., L. Kucharb, and C.J. Swanton. 1998. Estimation of solar radiation for use in crop modeling. Agric. For. Meteorol. 91:293-300.

Idso, S.B. 1981. A set of equations for full spectrum and 8-14 $\mu \mathrm{m}$ and $10.5-12.5 \mu \mathrm{m}$ thermal radiation from cloudless skies. Water Resour. Res. 17:295-304.

Idso, S.B., and R.D. Jackson. 1969. Thermal radiation from the atmosphere. J. Geophys. Res. 74:3397-3403.

Jordan, C.F. 1969. Derivation of leaf area index from quality of light on the forest floor. Ecology 50:663-666.

Kustas, W.P., and C.S.T. Daughtry. 1990. Estimation of the soil heat flux/.net radiation ratio from spectral data. Agric. For. Meteorol. 49:205-223.

Liu, X., X. Mei, Y. Li, Q. Wang, J.R. Jensen, Y. Zhang, and J.R. Porter. 2009. Evaluation of temperature-based global solar radiation models in China. Agric. For. Meteorol. 149:1433-1446.

Maas, S.J. 1988. Using satellite data to improve model estimates of crop yield. Agron. J. 80:655-662.

Maas, S.J. 1993. Parameterized model of gramineous crop growth: II. Within-season simulation calibration. Agron. J. 85:354-358. 
Meek, D.W., and J.L. Hatfield. 1994. Data quality checking for single station micrometeorological databases. Agric. For. Meteorol. 69:85-109.

Meek, D.W., J.H. Prueger, W.P. Kustas, and J.L. Hatfield. 2005. Determining meaningful differences for SMEX eddy covariance measurements. J. Hydrometeorol. 6:805-811.

Meza, F., and E. Varas. 2000. Estimation of mean monthly solar global radiation as a function of temperature. Agric. For. Meteorol. 100:231-241.

Novak, M.D. 2005. Soil temperature. p. 105-129. In J.L. Hatfield and J.M. Baker (ed.) Micrometeorology in agricultural systems. Agron. Monogr. 47. ASA, CSSA, and SSSA, Madison, WI.

Perez, I.A., M.L. Sanchez, M.A. Garcia, and B. de Torre. 2009. A classification of $\mathrm{CO}_{2}$ concentrations based on a binary meteorological six variable system. Agric. For. Meteorol. 149:1686-1692.

Rajan, N., and S.J. Maas. 2009. Mapping crop ground cover using airborne multispectral digital imagery. Precis. Agric. 10:304-318.

Richardson, A.J., and C.L. Wiegand. 1977. Distinguishing vegetation from soil background information. Photogramm. Eng. Remote Sens. 43:1541-1552.

Ritchie, G.L., D.G. Sullivan, W.K. Vencill, C.W. Bednarz, and J.E. Hook. 2010. Sensitivities of normalized difference vegetation index and a green/red ratio index to cotton ground cover fraction. Crop Sci. 50:1000-1010.

Swinbank, W.C. 1963. Long-wave radiation from clear skies. Q. J. R. Meteorol. Soc. 89:339-348.

Weiss, A., C.J. Hays, Q. Hu, and W.E. Easterling. 2001. Incorporating bias error in calculating solar irradiance: Implications for crop yield simulations. Agron. J. 93:1321-1326.

Wiegand, C.L., A.H. Gerbermann, K.P. Gallo, B.L. Blad, and D. Dusek. 1990. Multisite analyses of spectral-biophysical data for corn. Remote Sens. Environ. 33:1-16.

Wiegand, C.L., and J.L. Hatfield. 1988. The spectral-agronomic multisite-multicrop analyses (SAMMA) project. Int. Arch. Photogramm. Remote Sens. 27(B7):696-706.

Wright, J.L. 1982. New evapotranspiration crop coefficients. J. Irrig. and Drain. Div. 108:57-74.

Zheng, G., and L.M. Moskal. 2009. Retrieving leaf area index (LAI) using remote sensing: Theories, methods and sensors. Sensors 9:2719-2745. 